\title{
Application of Whole Process Cost Control in Construction Engineering Field
}

\author{
Wei Li \\ Chongqing Vocational Institute of Engineering China,Chongqing402260
}

Keywords: Engineering project; Cost control; Whole process

\begin{abstract}
The construction project is a costly project, and waste of resources has always been a common phenomenon in construction projects. The construction cost control should be from the whole process point of view, in order to effectively control the cost within a reasonable range. In this paper, the author makes a simple analysis of the whole process cost control.

In the past few decades, China's construction industry showed a trend of rapid development, and it has become the present stage of our national economic growth pillar industries, both the management level and construction technology have been significantly improved, but from the current status of the construction industry, there is still a big gap with the developed countries. Under the influence of market economy, China's construction industry gradually on the right track, and start with international standards, and project cost management of construction enterprises has attracted attention, especially with the real estate policy, it has become more and more serious which brings new challenges to the construction industry, and some enterprises began to learn from the successful experience of foreign countries. Achieved remarkable results, and further promote the development of China's construction industry.
\end{abstract}

\section{Overview of the Whole Process Cost Control of Engineering Projects}

Content of Cost Control in the Whole Process. The whole process of cost control is in the process of project construction, the scientific and reasonable means to control resources and waste materials, the actual production cost control in the reasonable scope, provide an important guarantee for the economic benefit of construction enterprises. In any project, the cost control of the project is a crucial link, which plays a guiding role in the whole process of the project. From the engineering project investment project that has been to the whole process of the late completion of the settlement, every step needs reasonable cost control, so as to achieve the goal of project cost control to ensure that the enterprise will not be a loss.

The importance of cost Control in the Whole Process. With the further development of the construction industry, enterprises gradually realize the control of the project cost control that should not be limited to the stage of construction, but standing in the global perspective for the cost of the whole project life cycle from control, in order to achieve the goal of cost control and to ensure the maximum comprehensive benefits of engineering project. Based on this background, the entire process cost control has become an important part of the construction industry, and scientific and complete cost control management is conducive to promoting the stability of the construction industry forward. In the actual management, it should be combined with the engineering needs and characteristics of reasonable cost control scheme, especially the different stages of projects and cost control in the target that is not the same as the corresponding control, and it means there will be different. In the construction industry, the project should be strengthened and complement, and draw on mature experience to ensure the quality of construction on the basis of reasonable control of the project cost. In short, the entire process cost control is an important guarantee for the smooth development of the project, but it also an important guarantee for the economic benefits of the relevant units of the project, especially for the steady development of the construction industry. 


\section{Status Analysis of Cost Control in the Whole Process}

Lack of Scientific Bidding Methods. With the development of market economy system, all kinds of economic entities are increasing constantly, which makes the market competition more and more fierce. In the construction industry, developers need scientific and rational selection of contractors, which plays a very important role in controlling the cost of the project. At present, the comprehensive evaluation method and the lowest price method are mainly adopted in the bidding process, but these methods are more easily affected by human factors, which leads to the unscientific evaluation results. In the bidding stage, the project cost is the key problem, some contractors are often used by low price, then passing way to get extra income that has adverse effects on the development of the construction industry. Therefore, in the bidding stage of the project, with the scientific selection of contractors, controlling of project cost is particularly important.

Ignore the Management of the Project Cost in the Prophase. In the process of project construction, some construction enterprises especially the whole process of cost control lack of awareness, it will mainly focus on cost control in construction stage ignoring the cost control of the project and resulting in unnecessary waste of resources. In every link of the whole process of the project, the cost will be incurred, so the effective cost management should be carried out from the whole process of the project.

Construction Cost Management at Construction Stage. It is a long time from the project to the completion of the project, and the construction stage is the process of building from scratch, so it occupies a very important position in the whole process of the project. In the construction stage, it is also the main stage of various resource consumption, and also the important stage of construction cost management. In the actual construction, there will be some human factors or uncertain factors over budget situation, such as the design change procedures which is not timely, the management is not in place, the material quality is not qualified, and it will be direct or indirect costs. Therefore, in this stage, the cost management is very important, and it plays an important role in the control of the total cost of the project.

Easy to Have Over-Estimation in Completion Settlement Phase. It is not easily calculated in accordance with the provisions in the stage of completion settlement of some projects, and there are more small buckle and so on, or other factors caused by the construction unit and the employer appear prevarication responsibility which make the settlement time.

Lack of Sound Laws and Regulations. The construction project is more complex involving the scope and content of many laws and regulations, inevitably there will be some blind that can not fully meet the management on the construction of the market economy environment, leading to the existence of no legal problems in project cost control and the real impact of the reliability of Engineering cost.

Inadequate Preparation. Due to the lack of the whole process cost management consciousness, some construction companies ignoring the correct understanding of the preparatory work, and the work is not in place, such as the construction enterprise is often influenced by subjective consciousness determine the scale of the project; the intention is affected by construction unit, advisory unit cannot make the estimation of relative science; audit departments have strict examination, and some enterprises only attach importance to the supervision of the construction process leading to abuse of power behavior have occurred. In the long run, it will inevitably bring adverse effects to construction enterprises and increase the management difficulty.

\section{Application Analysis of Whole Process Cost Control in Construction Field}

Through the above content of the whole process of cost control, the author of the whole process of cost control in the construction field of the application as the followings:

Main Methods of cost Control in the Whole Process. The whole process cost control is the most effective and practical method to ensure the comprehensive benefit of the project, but the effective control method should be taken in order to play the biggest role. 
Cost Control Target is Set up in Stages. The whole process cost control is the cost control of project decision-making, design, construction and completion settlement. Therefore, in any stage, if the cost control is not good, it will inevitably affect the cost control of other stages. In order to avoid such problems, in the implementation of the whole process of cost control can be set by stages of the cost control target, and each stage is clearly the cost control target to provide guidance and make the whole process cost control more reasonable and objective.

Accurately Calculate and Control Investment Objectives. In the actual construction process of engineering project, the design change will happen frequently. If there is a big deviation in the construction drawing, the project cost exceeding budget is easy to happen. In order to reduce the adverse effects of design changes to the project cost, it should set up effective control of the investment target in the construction stage, and in strict accordance with the measurement, control costs to reduce the waste of funds and resources.

Strengthening Contract Management. The contract is an important document that the contractor and the employer must adhere to. It is the guarantee for the smooth development of the project and the standard of conduct for both parties. In order to reduce the contract dispute on the cost of the project, we must strengthen the management of the contract which plays the supervision and restraint function and behavior control on both sides of the contract to ensure the project can be carried out in accordance with the contract, and to ensure the economic interests of both sides.

\section{Application of Cost Control in the Whole Process}

Decision Phase. The investment decision of the project is the code of conduct for the developer's investment, and it is also the important basis for the latter. In the entire process cost control, we must first make the decision-making stage of cost control, and according to the construction project scale and standard to formulate scientific cost control plan. Project construction standards is an important basis which directly affect the project establishment, feasibility study and investment, so to develop appropriate standards of construction, reasonable evaluation of investment project risk analysis, and the possible problems that has impact on the relevant units of the income with finally reasonable cost control planning.

Design Phase. The design stage has more than $70 \%$ influence on the whole project cost. From the program design, preliminary design and construction drawing process scheme to control the engineering cost in the design phase, according to the target cost control of pre-setting, the price of materials, equipment to optimize the design, make the best use of materials, equipment and other schemes to improve the rate as much as possible to reduce the waste of resources, and to realize the cost control in the limit. In addition, the rational use of quota design is equally important. Quota design should be based on the actual situation of the project, and reasonable planning limits can ensure that the design plan to meet the construction needs.

Construction Stage. The construction phase is an important part of the design drawings into real, so in the construction stage to control the contents of the large, relatively complex that is also the most prone to problems, improper handling will have an impact on the whole process cost. Therefore, in the construction phase, it should be in strict accordance with the "strict, fine, quasi" and other principles according to the construction process of scientific. At the same time, regulators should play a supervisory role, strengthen the control of the cost of each link, especially for details, local needs can do a detailed record of funds for the subsequent completion of the settlement to provide protection.

Completion Settlement Phase. The project completion settlement stage is an important stage before the project that was officially put into use, and it can start the project cost control from two aspects: on the one hand to collect and cost related information, to ensure the completion of settlement stage the rationalization and standardization of the information management system, and it can make use of other methods, collection and collation of data; on the other hand, strict examination that means well completion settlement work. Reviewers must be aware of the importance of this link, carefully review to ensure that no omissions or errors occur, and control of funds is reasonable. 


\section{Summary}

through the analysis of the above content, it can be clear that the whole process of cost control is very important in the field of construction process, to ensure the quality of the project on one hand plays the role and to adapt to the objective economic law under the market economy system, through the reasonable control of the project cost saving cost, and realize the project economy benefit and social benefit and win-win goal. In order to achieve this goal, in actual work, the need to start from the project investment project to complete the settlement process, the implementation of scientific cost control to ensure the smooth development of project and put into use. With the further development of the construction industry, construction enterprises should continue to explore and research, and strive to find more effective ways to control the cost of construction.

\section{Reference}

[1]Zixin Zhang, Peipei Wang. Analysis of problems and countermeasures in construction cost management[J].Small and Medium-sized Enterprise Management and Technology (a),2016(01):33-34.

[2]Jin Zhu.Analysis on construction process cost control[J]. Shanxi Architecture, 2016(09).

[3]Qiao Liu.Application of whole process cost control in construction engineering field[J].Chinese New Technology, New Products,2016(18):155-156. 